\title{
Viral hepatitis associated hepatocellular carcinoma on the African continent, the past, present, and future: a systematic review
}

Ottovon Bismark Dakurah ${ }^{{ }^{*}}$, Cynthia Raissa Tchuem Tamandjou ${ }^{2}$, Moleen Zunza ${ }^{3}$, Wolfgang Preiser ${ }^{4}$ and Tongai Gibson Maponga ${ }^{4}$

\begin{abstract}
Background: Hepatocellular carcinoma (HCC) is one of the leading causes of cancer-related deaths in Africa. In Africa, the major causes of HCC include chronic infection with hepatitis B virus (HBV) and/or hepatitis C virus (HCV). Knowledge of the changes in the incidence of viral hepatitis-associated HCC over time and the factors responsible for such changes is key in informing policies for the prevention of viral hepatitis-associated HCC in Africa.

Aim: The study aimed to systematically summarize the changes in the prevalence of viral hepatitis among HCC patients and the overall effect of the prevalence of viral hepatitis on the incidence of HCC over the past four decades in Africa (1980-2019).
\end{abstract}

Methods: A literature search was conducted in MEDLINE (PubMed), Google Scholar, Science Direct, Scopus, Web of Science, and African wide web for articles published on viral hepatitis-associated HCC in Africa from 1980 to 2019.

The abstracts of the articles were screened for eligibility and those meeting the inclusion criteria were retrieved and reviewed.

Results: A total of 272 studies were included in the analysis. Viral hepatitis-related HCC incidence changed by $1.17 \%$ (95\% confidence interval (Cl): $0.63-1.71, p<0.001$ ), 0.82\% (95\% Cl: $0.45-1.18, p<0.001$ ), and 3.34\% (95\% Cl: $2.44-4.25, p<0.001$ ) for every $1 \%$ change in the prevalence of HBV, HCV, and hepatitis D virus (HDV) respectively, per decade. The incidence of HBV-related HCC decreased by $-0.50 \%(95 \% \mathrm{Cl}:-0.74--0.25, p<0.001)$ over the last 40 years, while HCV-related HCC increased.

Conclusion: Overall, the incidence of viral hepatitis-associated HCC has not declined, mainly due to no decline in the prevalence of HCV, HDV, and the high number of chronic hepatitis B carriers on the African continent. There is an urgent need for the allocation of resources for the implementation of treatment and preventive programs for HBV, HCV, HDV, and HCC in Africa.

This systematic review is registered with PROSPERO ${ }^{\oplus}$, number CRD42020169723.

Keywords: Hepatocellular carcinoma, Hepatitis B virus, Hepatitis C virus, Hepatitis D virus, Africa, Sub-Saharan Africa, Direct-acting antivirals (DAAs)

\footnotetext{
* Correspondence: 22204911@sun.ac.za

${ }^{1}$ African Cancer Institute, Department of Global Health, Faculty of Medicine and Health Sciences, Stellenbosch University, Cape Town, South Africa

Full list of author information is available at the end of the article
}

(c) The Author(s). 2021 Open Access This article is licensed under a Creative Commons Attribution 4.0 International License, which permits use, sharing, adaptation, distribution and reproduction in any medium or format, as long as you give appropriate credit to the original author(s) and the source, provide a link to the Creative Commons licence, and indicate if changes were made. The images or other third party material in this article are included in the article's Creative Commons. licence, unless indicated otherwise in a credit line to the material. If material is not included in the article's Creative Commons licence and your intended use is not permitted by statutory regulation or exceeds the permitted use, you will need to obtain permission directly from the copyright holder. To view a copy of this licence, visit http://creativecommons.org/licenses/by/4.0/ The Creative Commons Public Domain Dedication waiver (http://creativecommons.org/publicdomain/zero/1.0/) applies to the data made available in this article, unless otherwise stated in a credit line to the data. 


\section{Background}

\section{Epidemiology of HCC}

Hepatocellular carcinoma (HCC), also known as primary liver cancer, is a disease of global significance due to its high incidence and mortality rates. HCC is the sixth most common cancer worldwide [1]. However, it is the fourth most common cancer in Africa, with differences in prevalence and etiology between North Africa and sub-Saharan Africa (SSA). This variation appears to be due to the varying prevalence of the underlying risk factors for HCC between the different regions [2]. The age-standardized incidence rate (ASIR) of HCC is reported as 6.3/100,000persons/ year, 8.6/100,000persons/year, 10.3/100,000persons/ year for North Africa, Southern SSA, and Eastern SSA, respectively. Central and Western SSA show the highest incidence of HCC of 16.9/100,000persons/year [3]. Among the top fifteen countries with the highest incidence of HCC in the world, the African continent alone contributes six of these countries [4].

The number of new HCC cases increased from 746, 000 in 2012 to 841,080 in 2018, which represents $5 \%$ of all cancers globally. Most of these cases were in Asia and Africa [5]. The number of HCC cases is projected to further increase to $1,361,836$ by 2040 because of population growth and the slow change in the epidemiology of viral hepatitis [6].

Due to its high mortality rate, $\mathrm{HCC}$ is the second most common cause of cancer mortality worldwide [7]. About 782,000 deaths due to HCC occurred in 2018, which represents $8.2 \%$ of all cancer-related deaths worldwide. Most of these deaths were recorded in the World Health Organization (WHO) AsianPacific and African regions [8].

\section{Risk factors for HCC}

HCC follows a prolonged period of chronic inflammation of the liver as a result of several factors. HBV, HCV, hepatitis D virus (HDV), alcohol abuse, aflatoxin exposure, dietary iron overload, diabetes mellitus, and obesity are the major risk factors for HCC, globally [2]. Viral risk factors especially chronic infections with $\mathrm{HBV}$ or $\mathrm{HCV}$ are the most common agents related to the development of HCC worldwide in comparison to environmental and behavioral risk factors such as alcohol consumption, obesity, smoking, and exposure to aflatoxins [9]. Globally, 44\% of HCC cases are attributed to chronic HBV infection (CHB) while $21 \%$ of the cases are attributed to chronic HCV infections [10]. Moreover, $39.1 \%$ of HCC deaths have been HBV-related while $29.1 \%$ are due to HCV infection, globally $[11,12]$. Due to the high attributable fraction of $\mathrm{HCC}$ due to $\mathrm{CHB}$, HBV has been coined as the "second-most carcinogenic agent after tobacco" [13].
The incidence of HBV- and HCV-related $\mathrm{HCC}$ varies between North Africa and SSA due to variations in the prevalence of infections of the two viruses. HBV contributes 18 and $70 \%$, while $\mathrm{HCV}$ is responsible for 60 and $20 \%$ of HCC in North Africa and SSA respectively [14]. However, data on the incidence of HCC in most SSA countries are usually either non-existent or inaccurate, which results in a significant underestimation of the tumor in Africa [4, 15].

\section{Contribution of viral hepatitis to HCC in Africa}

About 2 billion people have been infected with HBV globally, of whom 248 million are chronic carriers of the virus and are at an increased risk of liver cirrhosis and HCC [16]. The overall estimated prevalence of $\mathrm{CHB}$ on the African continent is $6.1 \%$, with SSA carrying the largest number of 78 million infections $[17,18]$. In SSA, Central Africa has the highest CHB prevalence of $9.7 \%$ among adults followed by West Africa with an $8.3 \%$ prevalence. Eastern SSA and Southern SSA have a 5.5 and $3.8 \%$ prevalence of $\mathrm{CHB}$, respectively. North Africa has the lowest prevalence of $\mathrm{CHB}$ of $2.8 \%$ [19].

An estimated 71.1 million people are currently chronic carriers of HCV worldwide, with about 18 million of these being in Africa and at risk of $\mathrm{HCC}$ development $[18,20]$. In SSA, the prevalence is estimated at $2.1-3.3 \%$ while North Africa has a prevalence of $\mathrm{HCV}$ of $2.3-7.7 \%$ [19].

HDV is a negative-strand ribonucleic acid virus that requires $\mathrm{HBV}$ for its proliferation [21]. Globally, 5\% of $\mathrm{HBV}$-infected individuals are co-infected with HDV, with SSA being one of the regions with the highest prevalence $(8.39 \%)[22,23]$. The synergistic effect of $\mathrm{HBV} / \mathrm{HDV}$ co-infection leads to rapid progression to liver cirrhosis and $\mathrm{HCC}$ compared to HBV alone [24, 25].

The epidemiological transition of viral hepatitisassociated $\mathrm{HCC}$ for the past four decades in Africa remains poorly described. A clear understanding of these transitions over time and the factors that could influence such changes are key for informing priority areas of intervention for the prevention of viral hepatitis-associated HCC in Africa. This study sought to provide information on the changes in the prevalence of viral hepatitis among HCC patients and the overall effect of the prevalence of viral hepatitis on the incidence of HCC over the past four decades in Africa.

\section{Materials and methods}

The study protocol was designed and reported following Preferred Reporting Items for Systematic Reviews and Meta-Analysis Protocol (PRISMA) guidelines. 


\section{Literature search method}

We conducted a systematic literature search per PRIS MA guidelines, in MEDLINE (PubMed), Science Direct, Web of Science, Google Scholar, Scopus, and AfricaWide Information for studies published between January 1980 and Dec 2019 and describing viral hepatitis (HBV, $\mathrm{HCV}$, and HDV), and HCC in Africa. The search terms included ((("viral hepatitis"[Title/Abstract] OR viral hepatitis [Title/Abstract] OR Hepatitis, Viral, Human [Title/Abstract] OR Human Viral Hepatitis [Title/Abstract])) OR (viral hepatitis OR Hepatitis, Viral, Human OR Human Viral Hepatitis [MeSH Terms])) AND ((("hepatocellular carcinoma”[Title/Abstract] OR Carcinoma, Hepatocellular [Title/Abstract] OR Adult Liver Cancer [Title/Abstract] OR Liver [Title/Abstract] OR Hepatoma Cancer AND, Adult [Title/Abstract])) OR (hepatocellular carcinoma OR Carcinoma, Hepatocellular OR Adult Liver Cancer OR Liver OR Hepatoma [MeSH Terms])) AND ((Africa [Title/Abstract]) OR Africa $[\mathrm{MeSH}$ Terms]).

Titles and/or abstracts were screened to decide the relevance of the studies and the full text of selected studies was retrieved and reviewed. The reference lists of relevant studies were also assessed to find additional studies. The last search was conducted on 31 March 2020, and the search was limited to studies published in English and/or French languages. The languages were limited to English and French because these are the two languages the researchers understand. Duplicated studies and all references were removed and managed by the bibliographic management tool Mendeley Desktop version 1.19.4. The literature search is illustrated in Fig. 1.

\section{Inclusion/exclusion criteria}

All published articles in peer-reviewed journals on viral hepatitis and viral hepatitis-associated HCC on the African continent in the English and French languages between January 1, 1980, and Dec 31, 2019, were assessed for eligibility for inclusion in the study. Studies reporting on the detection of hepatitis B surface antigen (HBsAg), or anti-hepatitis delta antibody (anti-HDV), or HDV RNA, or anti-hepatitis C antibody (anti-HCV), or HCV RNA, with a detailed description of the participants' selection or inclusion criteria and laboratory methods
Records identified through database searching ( $n=22967)$ PubMed: 9482, Google scholar; 12150, Scopus: 250, Web of science: 400 , ScienceDirect: 405. Africa-wide: 280.

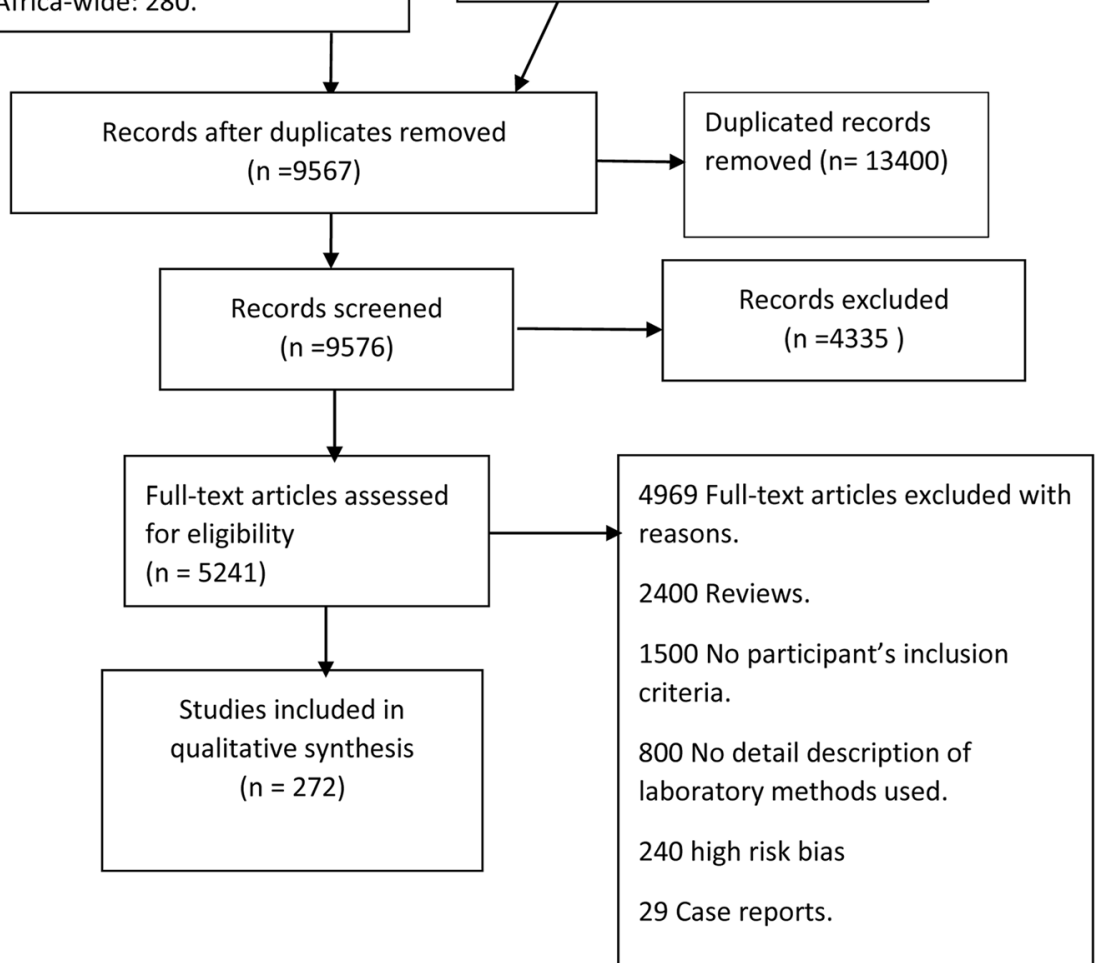


used, were included in the study. Studies that reported on first-time HCC diagnosis through histology, and/or imaging, and/or biochemical tests were also included. Reviews, case reports/series, editorials, commentaries, and letters were excluded. Research on hepatitis A virus (HAV) and hepatitis E virus (HEV) was excluded because these viruses do not typically cause chronic infections except on few occasions where HEV may cause chronic infections in immunocompromised individuals which can lead to HCC. However, there were no restrictions on the gender of participants, ethnic groups, cultural behavior, or professional activities.

\section{Data extraction and quality assessment}

We extracted details of study publication year, authors name, journal name, the prevalence of $\mathrm{HBV}, \mathrm{HCV}$, and $\mathrm{HDV}$, the incidence of $\mathrm{HCC}$, participants demographics (mean age, gender proportions), sample size, country of research, and type of study population. The risk of bias in individual studies was assessed using the Joanna Briggs bias assessment tool for prevalence studies 2017. The quality of studies was assessed by three of the authors (OBD, TGM, and CRT). Discordances were resolved on the quality of a study by discussions. All three authors were involved in the selection of included and excluded articles. This was done to prevent inclusion and exclusion bias.

\section{Statistical analysis}

The calculated prevalence of HBV, HCV, and HDV was determined by calculating the number of positive subjects divided by the total number of subjects screened. The incidence of HCC was determined by the total combined number of new cases divided by the total combined adult population at risk. The studies' heterogeneity was quantified by $\mathrm{I}^{2}$ statistics. We assessed the effect of time on $\mathrm{HBV} / \mathrm{HCV} / \mathrm{HDV}$ prevalence, and the incidence of HCC in the random-effects models by calculating the change in the prevalence of each virus with respect to $\mathrm{HCC}$ incidence related to that virus in a decade. The effect of the prevalence of $\mathrm{HBV}, \mathrm{HCV}$, and HDV on the incidence of HCC was also assessed using the random-effects model by calculating the percentage (\%) change in the incidence of viral hepatitis-related HCC with respect to $1 \%$ change in the prevalence of each virus. This model was used to combine the data of primary outcomes, due to the existence of high-level heterogeneity in-between studies. The random effect model determines how much of the variability in the estimates is due to the study differences (study population, age, sex, geographical location, and study design) and how much is due to chance. The pooled prevalence was adjusted for studies heterogeneity and impact of sample size. Box and whisker plots were used to give a visual representation of the changes in the trend of the prevalence of $\mathrm{HBV}, \mathrm{HCV}$, and $\mathrm{HDV}$ and the incidence of HCC over the period. The statistical significance level was set at $p<0.05$. All analyses were done using Stata 16.0 (Stata Corp, College Station, Texas, USA).

\section{Results}

\section{Studies selection and characteristics}

Of the 22,967 studies identified and screened, 272 met the study eligibility criteria and were included as shown in Fig. 1. Data on HBV prevalence was available for 244 studies, while 187 studies had HCV prevalence data. Data on HDV was available from 52 studies. HBV and $\mathrm{HCV}$ co-infections were reported in 50 studies while 45 studies reported on $\mathrm{HCC}$ related to $\mathrm{HBV}, \mathrm{HCV}$, and HDV. West Africa had the highest number of studies on the prevalence of HBV and HDV co-infection as shown in Figs. 2 and 3. Egypt in North Africa had the highest number of HCV prevalence (Fig. 4) and viral hepatitisrelated HCC studies. The changes (\%) in the prevalence of $\mathrm{HBV}, \mathrm{HCV}, \mathrm{HBV} / \mathrm{HCV}$, and $\mathrm{HDV}$, as well as the change in the incidence of HCC, are shown in Table 1. The percentage (\%) change in prevalence between each of the viruses (HBV, HCV, and HDV) and HCC are also shown in Table 2. The subregional analyses of the contribution of $\mathrm{HBV}, \mathrm{HCV}$, and HDV to HCC incidence in SSA and North Africa are shown in Table 3.

\section{Prevalence of HBV among HCC cases and incidence of HCC between 1980 and 2019}

Two hundred and forty-four studies were identified for HBV prevalence and were included in the random-effect meta-regression analysis. From the analysis, the prevalence of HBV in HCC cases changed by $-0.50 \%$ (95\% confidence interval (CI): $-0.74--0.25)$ per decade over the four-decade period (Table 1). This change in prevalence was statistically significant $(p<0.001)$ and can be graphically observed in Fig. 5. HBV-related HCC had a change in the incidence of $1.17 \%$ (95\% CI: $0.63-1.71$, $p<0.001$ ) for every $1 \%$ change in the prevalence of HBV (Table 2). The prevalence of co-infection of HBV and $\mathrm{HCV}$ in $\mathrm{HCC}$ cases also had a significant change of $0.21 \%$ (95\% CI: $-0.30--0.12, p<0.001$ ) per decade over the 4 decades. In the subregional analyses, HBV contributed $65.8 \%$ (95\% CI: 39.1-68.3) and 29.1\% (95\% CI: 10.3-32.7) of viral hepatitis-associated HCC in SSA and North Africa respectively (Table 3).

\section{Prevalence of HCV among HCC cases and incidence of HCC}

One hundred and eighty-seven studies reporting on the $\mathrm{HCV}$ prevalence were identified and included for the random-effect meta-regression analysis. However, there was no data on HCV-related HCC for the first decade 


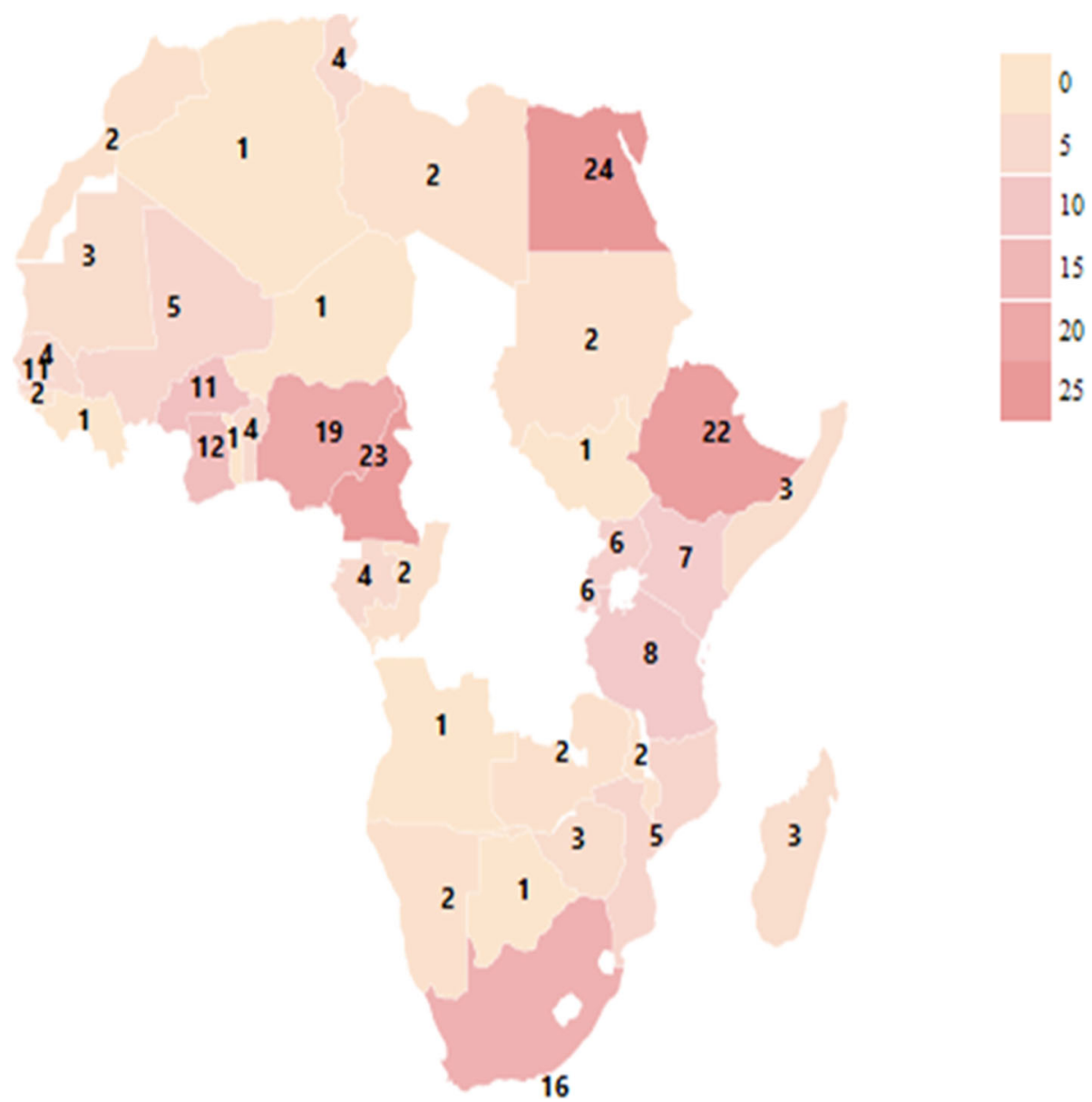

Fig. 2 A heat map of Africa showing the distribution of HBV prevalence studies included in the systematic review. The numbers shown represent the number of eligible studies identified in each of the countries. Egypt has the highest number of eligible HBV studies $(n=24)$, followed by Cameroon $(n=22)$, identified, and included in the study. (Map generated from https://geographicheatmap.blogspot.com)

(1980-1990). An increase in the prevalence of HCV among HCC cases was observed over the four-decade period (1980-2019) as shown in Fig. 5, though not statistically significant. $\mathrm{HCV}$ prevalence in $\mathrm{HCC}$ cases changed by $-0.89 \%$ (95\% CI: $-0.49-0.31, p=0.66)$ per decade over the four-decade period (Table 1). HCVrelated $\mathrm{HCC}$ had a change in incidence of $0.82 \%(95 \%$ CI: $0.45-1.18, p<0.001)$ for every $1 \%$ change in the prevalence of HCV on the continent (Table 2). The subregional analyses also showed that $\mathrm{HCV}$ contributed 26.8\% (95\% CI: 16.9-35.1) and 46.5\% (95\% CI: $11.2-$ 48.6) of viral hepatitis-related HCC cases in SSA and North Africa, respectively.

\section{Prevalence of HDV among HCC cases and incidence of HCC}

Fifty-two studies reported on HDV prevalence and were included in the random-effect meta-regression analysis. A gradual increase in $\mathrm{HDV}$ among $\mathrm{HBV}$-related $\mathrm{HCC}$ cases is observed in Fig. 6. The prevalence of HDV in HCC cases change by $0.01 \%$ (95\% CI: $-0.31-0.33$ ) per decade in the four decades, but this change was not statistically significant $(p=0.95)$ (Table 1$)$. HBV/HDV-related HCC had a change in the incidence of $3.34 \%$ (95\% CI: $2.44-4.25, p<0.000)$ for every $1 \%$ change in HDV prevalence (Table 2). HBV/HDV co-infection contributed 14.8\% (95\% CI: 8.7-18.4) and 21.2\% (12.3-25.6) of viral hepatitis-related HCC cases in SSA and North Africa respectively in the subregional analysis.

Incidence of viral hepatitis- associated HCC between 1980 and 2019

Forty-five studies on viral hepatitis-related HCC incidence were included in the analysis. The incidence of viral hepatitis-related HCC increased steadily over the four decades (1980-2019) as indicated in Fig. 7. The incidence of viral hepatitis-related HCC was 29.9/100, 000persons/year for the period 1980-1990, 48.8/100, 


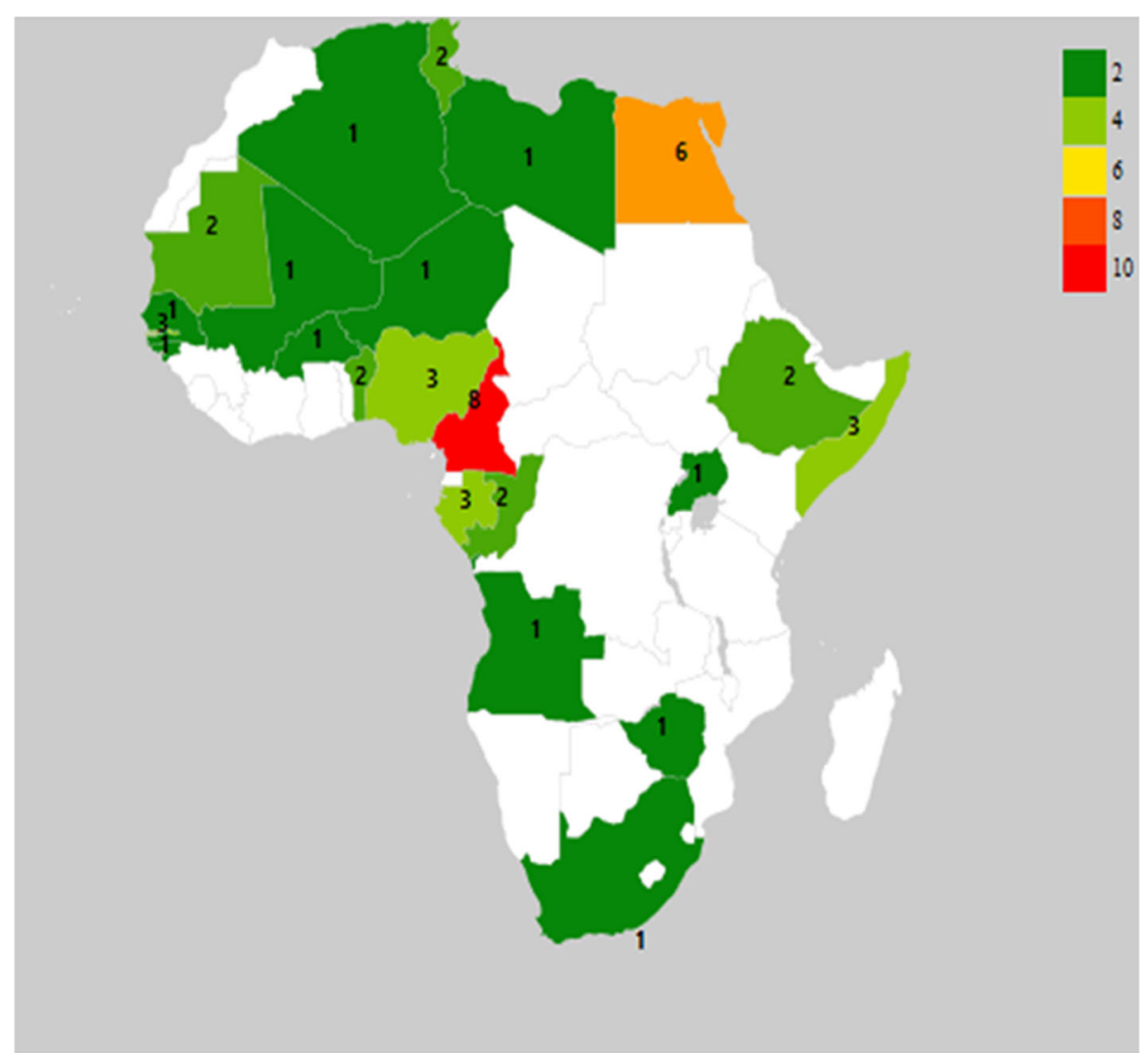

Fig. 3 A heat map of Africa showing the distribution of HDV prevalence studies included in the systematic review. Cameroon has the highest number of eligible HDV studies ( $n=8)$ while Egypt had the second-highest eligible HDV studies $(n=6)$ identified and included in the study (Map generated from https://geographicheatmap.blogspot.com)

000persons/year for the period 1991-2000, 55.3/100, 000persons/year for the period 2001-2010, and 69.5/ 100,000persons/year for the period 2011-2019. The median onset age of HCC was 47 years and the male to female ratio among $\mathrm{HCC}$ cases was 3:1. In the randomeffect meta-regression analysis, we found that the incidence of viral hepatitis-related HCC changed by $1.52 \%$ (95\% CI: -4.26 - 7.29) each decade over the fourdecade period but this was not statistically significant $(P=0.61)$. In comparing the prevalence of $\mathrm{HBV}$ and $\mathrm{HCV}$ among $\mathrm{HCC}$ cases over the 40 years, there was a slight decline in $\mathrm{HBV}$ prevalence while $\mathrm{HCV}$ prevalence increased.

\section{Discussion}

Viral hepatitis is largely responsible for the incidence of HCC across the globe. The prevalence of chronic viral hepatitis (mostly HBV and HCV) has been strongly associated with the incidence of HCC in many studies across the world $[2,5,18]$. Therefore, it is important to understand the trends of the prevalence of $\mathrm{HBV}$ and $\mathrm{HCV}$ on the African continent in making policies and recommendations for the prevention of viral hepatitis-related HCC.

\section{Effect of HBV}

The number of studies on viral hepatitis-associated HCC began to increase from the 1990s. Increased diagnosis capacity and funding for viral hepatitis research on the continent could be responsible for this observation. Studies on HBV were fairly distributed evenly across the continent while most studies on HCV came from Egypt. HBV contributes the highest number of HCC cases in the world, especially in Africa where CHB is highly endemic $[9,12]$. The risk of developing HBV-related HCC is 223 times high in patients with $\mathrm{CHB}$ compared to non-infected individuals [26]. In the current study, the prevalence of HBV was found to decline among HCC cases between 1980 and 2019. This finding was consistent with studies conducted in Asia [27]. The decline in HBV prevalence is likely a direct result of the increased coverage of childhood HBV immunization programs implemented across the African continent [28, 29]. 


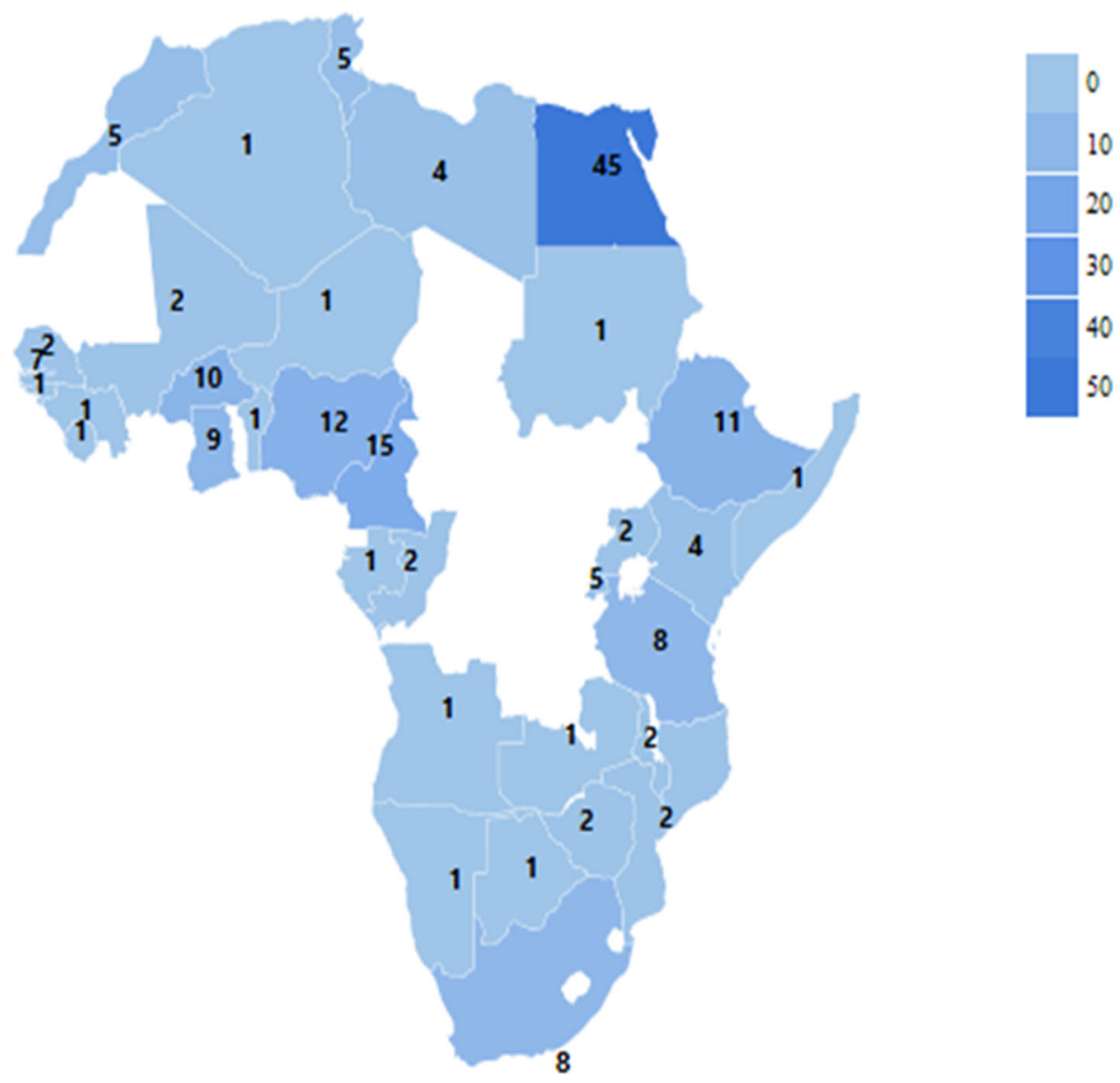

Fig. 4 A heat map of Africa showing the distribution of HCV prevalence studies included in the systematic review. The numbers on the map represent the number of eligible studies identified in each country. Egypt has the highest number of eligible studies on HCV $(n=45)$ identified and included in the study (Map generated from https://geographicheatmap.blogspot.com)

Childhood HBV vaccination has been effective in reducing the infection rates of HBV worldwide [30] which results in fewer people developing CHB that progresses to HCC. Although the decline in HBV-related HCC cases is a remarkable achievement for the African continent, there is still a need for improvement in HBV birth dose vaccine coverage across the continent and treatment for those already infected. There are still some countries that have not fully implemented the HBV birth dose vaccine in their childhood immunization schedules [31].
HBV birth dose immunization is important because perinatally-acquired $\mathrm{HBV}$ infections are likely to progress to $\mathrm{CHB}$, leading to the development of HCC [32]. Increased political commitment from African governments to provide resources for the implementation of the HBV birth dose immunization programs is required. This will help in the complete elimination of $\mathrm{CHB}$ and its sequelae that includes liver cirrhosis and HCC [9]. Other strategies that could also contribute to the control of the African HBV epidemic include increased

Table 1 Change (\%) in the prevalence of HBV, HCV, HDV among HCC cases, and the incidence of HCC per decade from 1980 to 2019

\begin{tabular}{llll}
\hline Virus and HCC Incidence & Change (\%) & $95 \%$ confidence interval (Cl) & $p$-value \\
\hline HBV & -0.50 & $-0.74--0.25$ & $<0.001$ \\
HCV & -0.89 & $-0.49-0.31$ & 0.66 \\
HDV & 0.01 & $-0.31-0.33$ & 0.95 \\
HBV\&HCV co-infection & -0.21 & $-0.30--0.12$ & $<0.001$ \\
HCC incidence & 1.52 & $-4.26-7.29$ & 0.61 \\
\hline
\end{tabular}


Table 2 Change (\%) in the incidence of HBV, HCV, and HDV related HCC per $1 \%$ change in the prevalence of each virus

\begin{tabular}{llll}
\hline Virus & Change $(\%)$ & $95 \%(\mathrm{Cl})$ & $p$-value \\
\hline HBV-HCC & 1.17 & $0.63-1.71$ & $<0.001$ \\
HCV-HCC & 0.82 & $0.45-1.18$ & $<0.001$ \\
HDV-HCC & 3.34 & $2.44-4.25$ & $<0.001$ \\
\hline
\end{tabular}

awareness of HBV among the general population, improved safety in blood transfusions, safe tattooing, and hygienic traditional scarification [33].

\section{Effect of HCV}

$\mathrm{HCV}$ is the second major risk factor for HCC in Africa after HBV. Our findings showed an increase in the prevalence of $\mathrm{HCV}$ among HCC cases, and this is consistent with similar findings in the global liver cancer incidence by Lin et al. [12]. This increase may be attributed to the inadequate awareness of transmission routes of the virus and its complications, the unavailability of a vaccine, and limited access to direct-acting antiviral drugs (DAAs) [18]. Studies conducted in Ghana and Egypt among barbers and HCV-infected patients respectively demonstrated limited knowledge of HBV and HCV among the studied populations [34, 35]. For an improved understanding of the epidemiology of $\mathrm{HBV}$ and $\mathrm{HCV}$-induced HCC in Africa, there is a need for screening for viral infections, especially in high-risk populations such as prison inmates, commercial sex workers, people who inject drugs, and men who have sex with men, because early detection of the infection has better treatment outcomes and helps to prevent HCC development [33]. With reduced costs for testing and treatment, improved access to antiviral drugs (DAAs), increased awareness of the virus and its complications among the general population, and education and/or support for IDUs, the burden of $\mathrm{HCV}$ and $\mathrm{HCV}$-related $\mathrm{HCC}$ will decrease significantly on the African continent [36].

\section{Effect of HDV}

The prevalence of HDV in HBV-infected individuals increased gradually over the study period, although this increment was not statistically significant in the randomeffect analysis. The increased prevalence of HDV is of concern owing to the synergistic effect of HDV on the progression of HBV-related HCC [37]. The increasing prevalence of $\mathrm{HDV}$ among $\mathrm{HBV}$ infected individuals

Table 3 Contribution of HBV, HCV, and HDV to the incidence of HCC in SSA and North Africa

\begin{tabular}{llll}
\hline Subregion & HBV \% (95\% Cl) & HCV \% (95\% Cl) & HDV \% (95\% Cl) \\
\hline SSA & $65.8(39.1-68.3)$ & $26.8(16.9-35.1)$ & $14.8(8.7-18.4)$ \\
North Africa & $29.1(10.3-32.7)$ & $46.5(11.2-48.6)$ & $21.2(12.3-25.6)$
\end{tabular}

means these people are at increased risk of HCC compared to HBV mono-infected individuals. As indicated in our results, decreasing the prevalence of HDV by $1 \%$ decreases the incidence of HBV/HDV-related HCC by 3.34 times. The increasing prevalence of HDV underlines the need to prevent HBV infections since HDV requires HBV for its replication and carcinogenic activities $[24,25]$. Our subregional analyses further confirm this point because the increasing prevalence of HDV has resulted in increased HDV related HCC in both SSA and North Africa compared to similar findings in [23, 25].

From the analysis, there was a steady increase in the incidence of viral hepatitis-related HCC between 1980 and 2019. Our findings showed that the incidence of viral hepatitis-associated HCC increased by $1.52 \%$ each decade, but this was not statistically significant. The incidence could be higher and probably statistically significant if African countries had a better screening and diagnostic capacity for HCC, proper data capturing systems at cancer registries, and adequate cancer registries. The increasing trend in the incidence of viral hepatitisassociated HCC could be a result of the increasing prevalence of $\mathrm{HCV}$ on the African continent over the last 40 years. It could also be due to the limited access to antiviral drugs against $\mathrm{HBV}$ and $\mathrm{HCV}$; therefore, a significant number of the chronic carriers of $\mathrm{HBV}$ and $\mathrm{HCV}$ in the population have an increased risk of $\mathrm{HCC}$ and may eventually develop HCC later in life.

Despite the prevailing viral risk factors on the continent, there are other factors responsible for the increasing incidence of viral hepatitis-induced HCC in Africa. These factors include inadequate trained professionals such as hepatologists and radiologists in Africa [38] and fewer resources committed to the fight against viral hepatitis-related HCC by African governments over the years [15]. The selective attention due to limited resources committed by African governments could explain the mixed picture of viral contribution to $\mathrm{HCC}$ found in the subregional analyses. According to Bahri et al. [39] and Ndom [14], HBV contributed 70 and $18 \%$ of $\mathrm{HCC}$ in SSA and North Africa respectively while HCV contributed 20 and $60 \%$ of HCC in SSA and North Africa, respectively. However, in the current study, we found that HBV contributed 65.8 and $29.1 \%$ of viral hepatitis-related HCC in SSA and North Africa, respectively. $\mathrm{HCV}$ also contributed 26.8 and $46.5 \%$ of viral hepatitis-related HCC cases in SSA and North Africa, respectively. The decreased-increased scenario of $\mathrm{HBV}$ and $\mathrm{HCV}$-related $\mathrm{HCC}$ in Africa confirms the unequal attention and resources committed to the fight against these two viruses. It also calls for the sharing of policyimplementation strategies between African governments. African governments must work in cooperation and 


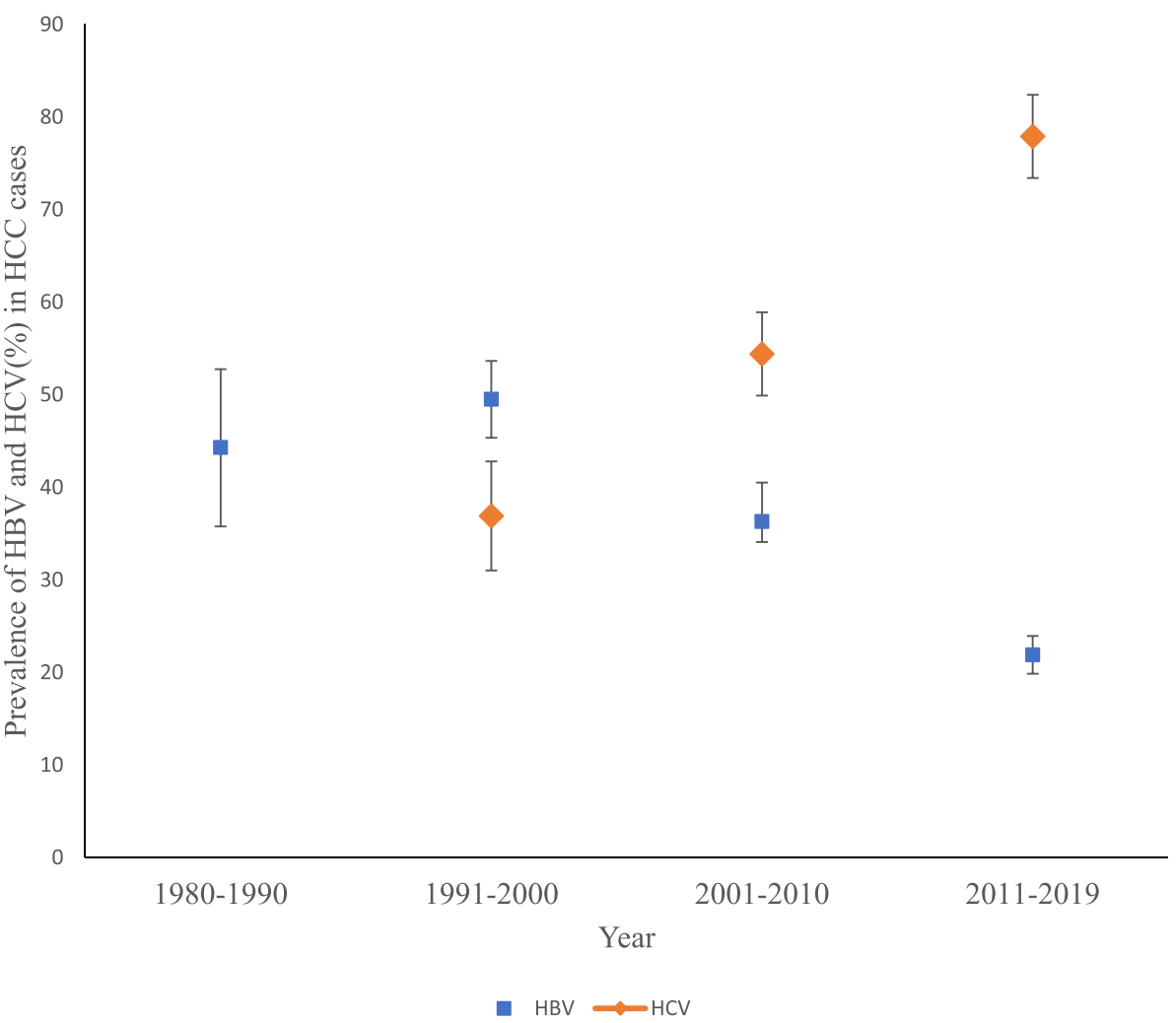

Fig. $5 \mathrm{~A}$ box and whiskers plot of the prevalence of HBV and HCV in hepatocellular carcinoma patients over four decades in Africa, between 1980 and 2019. HBV (blue box) prevalence among HCC cases decreased significantly while HCV (orange box) prevalence in the HCC cases increased over the study period (1980-2019). The box represents the mean estimate (prevalence), and whiskers correspond to the error margin $(\mathrm{HBV}=3.5 \%, \mathrm{HCV}=3.3 \%)$ around the estimated mean

commit enough resources towards the elimination of viral hepatitis and HCC on the continent.

However, our findings could be as result of improved testing capabilities, changes in healthcare practices, policies, and infrastructure rather than epidemiological changes because we do not have data on the overall incidence of HCC (viral and non-viral) in Africa. Therefore, these changes in $\mathrm{HBV} / \mathrm{HCV} / \mathrm{HDV}$ prevalence could be in part due to changes in how frequently these viruses are tested for in HCC patients over time.

The median age for the onset of $\mathrm{HCC}$ was 47 years and the male to female ratio in HCC cases was 3:1. These findings were consistent with another study by Kirk et al. in the Gambia [40]. The current age of onset of HCC in Africa (47 years) is the youngest in the world compared with other regions such as Japan (69 years), Europe (63 - 65 years), North America (62 years), Korea (57 years), and China (55 - 59 years) [1]. The early onset of HCC in Africa would result in loss of labor force and reduced productivity, resulting in an increased economic burden on the continent.

In contrast to the findings of the current study, studies conducted in Asia found a declining trend of HBV and
HCV-related HCC over a similar study period. Factors such as improved HBV vaccine uptake, increased access to both HBV and HCV antiviral drugs, and improved diagnostic tools were stated as being responsible for the decline in the incidence of HCC [27]. To significantly reduce the incidence of viral hepatitis-associated HCC in Africa, there should be an implementation of effective screening and preventive programs for chronic viral hepatitis in Africa and increased access to antiviral treatment for HBV and HCV. Our findings reaffirm the need for increased efforts in the prevention of $\mathrm{HBV}$ and $\mathrm{HCV}$ in the fight against $\mathrm{HCC}$ on the African continent. There is also a need for the implementation of effective surveillance systems that will aid in the prevention, early diagnosis, and treatment of HCC in Africa. Efforts should be made to minimize the other risk factors such as alcohol abuse, diabetes, aflatoxin exposure, smoking, and obesity as these factors can hasten the development of viral hepatitis-associated HCC. These factors can also be confounding factors in the disease (HCC) development process, and therefore can affect the evaluations of interventions for the prevention of viral hepatitis-associated $\mathrm{HCC}$ in Africa. Human immunodeficiency virus (HIV) 


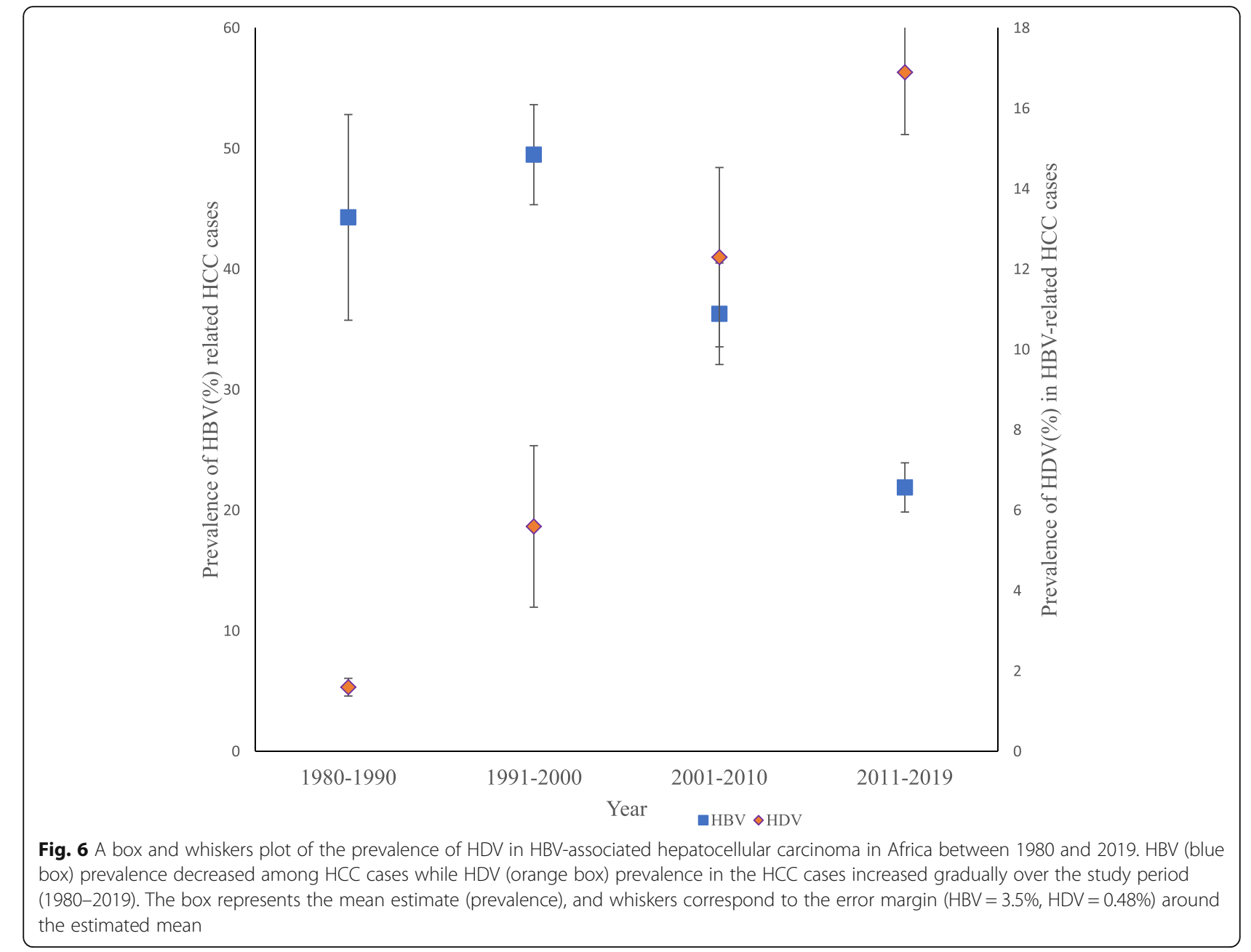

could also have an impact on the trends of HBV and $\mathrm{HCV}$, and the development of HCC in Africa. With HIV, HBV infections are likely to become chronic, therefore the development of HCC may occur quicker in HIV patients with chronic viral hepatitis than non-HIV infected individuals [41].

\section{Limitations}

The current study includes only articles published in the English and French languages; this left out quality articles that were published in other languages in Africa. Data on the overall incidence of HCC in Africa was not collected due to time constraints, so a comparison between total HCC cases and viral hepatitis-related HCC could not be done. Furthermore, many studies conducted in the 1980s did not clearly describe laboratory procedures, and when we contacted the authors, most of them did not respond. These studies were left out of this systematic review. Including them could probably have a different outcome in the results. Moreover, most of the studies were conducted over a longer period and therefore the year of publication did not necessarily reflect the incidence for that year. Also, none of the data was from a cancer registry of any country and this shows the fragmentation in the data gathering process in Africa, which could influence our results. Finally, since we could not look at the overall incidence of HCC in Africa (we looked at only viral hepatitis-related HCC) our findings could be as a result of improved testing capabilities in Africa rather than actual changes in the frequency viral hepatitis-related HCC. This is a limitation we would explore in our next research.

\section{Conclusion}

Viral hepatitis-associated HCC is still a major public health problem in Africa; HBV and HCV are responsible for a larger proportion of all HCC cases in Africa. Although efforts have been made by different role players including individual governments as well as regional and international health organizations to minimize the 


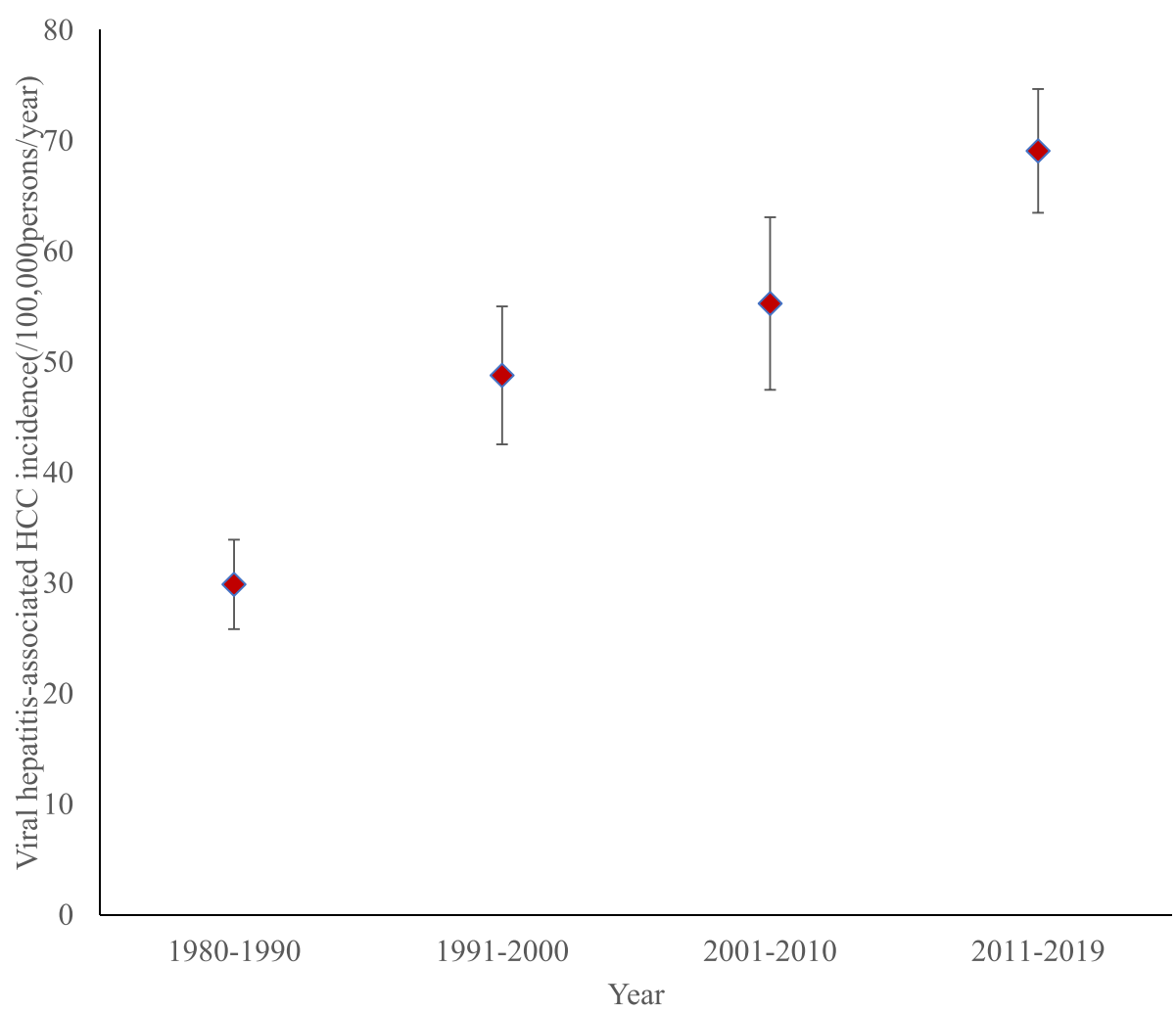

Fig. 7 A box and whiskers plot showing the trend of incidence of viral hepatitis-related hepatocellular carcinoma between 1980 and 2019 . Viral hepatitis-related hepatocellular incidence (blue box) increased over the study period covering 1980 to 2019. The incidence was 29.9/ 100,000person/year, 48.8/100,000persons/year, 55.3/100,000persons/year and 69.5/100,000person/year for the first (1980-1990), second (19912000), third (2001-2010) and the fourth (2011-2019) decades, respectively. The box represents the mean estimate (prevalence) and whiskers correspond to the error margin (3.2\%) around the estimated mean

infection rates of $\mathrm{HBV}$ and $\mathrm{HCV}$ in Africa, the prevention of $\mathrm{HBV}$-related $\mathrm{HCC}$ through $\mathrm{HBV}$ vaccination is yet to achieve maximum success. It is also clear from our findings that healthcare systems in Africa must prepare for the increasing number of patients with hepatitis-related $\mathrm{HCC}$ despite the implementation of prevention programs. Therefore, there is a need for increased and sustained efforts towards the elimination of $\mathrm{HBV}$ and HCV as public health concerns. To eliminate viral hepatitis and its sequelae such as cirrhosis and HCC, improved access to antiviral drugs for individuals infected with $\mathrm{HBV}$ and $\mathrm{HCV}$, implementation of control and preventive measures for $\mathrm{HBV}$ and $\mathrm{HCV}$, and increased funding for research into viral hepatitis for the African continent must be given priority by health policymakers.

\section{Abbreviations}

HCC: Hepatocellular Carcinoma; HBV: Hepatitis B virus; HCV: Hepatitis C virus; HDV: Hepatitis D virus; HAV: Hepatitis A virus; HEV: Hepatitis E virus; SSA: subSaharan Africa; WHO: World Health Organization; HIV: Human Immunodeficiency Virus; DAAs: Direct-Acting Antiviral drugs; CHB: Chronic Hepatitis B

\section{Acknowledgments}

We would like to thank the African Cancer Institute for supporting the research with funds.

\section{Authors' contributions}

OBD conceived the idea and wrote the study protocol, registered the study with PROSPERO ${ }^{\star}$, search for articles, extracted data, and drafted the manuscript. TGM helped in article search, data interpretation, and a major contributor to the writing of the manuscript. CRT helped in article search, data interpretation, and a major contributor to the writing of the manuscript. WP refined the research question and contributed to the writing of the manuscript. MZ analyzed the data and contributed to the writing of the manuscript. All authors revised and approved the final manuscript.

\section{Funding}

The African Cancer Institute (ACl) provided a bursary to support the study.

\section{Availability of data and materials}

The datasets used and analyses during the current study are available from the corresponding author on reasonable request.

\section{Declarations}

Ethics approval and consent to participate

Ethical approval and informed consent was waived by the Health Research Ethics Committee (HREC 2) at the Faculty of Medicine and Health Science, Stellenbosch University (HREC reference number: X19/10/041). 


\section{Consent for publication}

Not applicable.

\section{Competing interests}

The authors declare that they have no competing interests.

\section{Author details}

${ }^{1}$ African Cancer Institute, Department of Global Health, Faculty of Medicine and Health Sciences, Stellenbosch University, Cape Town, South Africa. 2Division of Health Economics, School of Public Health and Family Medicine, University of Cape Town, Cape Town, South Africa. ${ }^{3}$ Division of Epidemiology and Biostatistics, Department of Global Health, Faculty of Medicine and Health Sciences, Stellenbosch University, Cape Town, South Africa. ${ }^{4}$ Division of Medical Virology, Faculty of Medicine and Health Sciences, Stellenbosch University, Cape Town, South Africa.

\section{Received: 17 February 2021 Accepted: 20 May 2021}

\section{Published online: 19 June 2021}

\section{References}

1. Zakharia K, Luther CA, Alsabbak H, Roberts LR. Hepatocellular carcinoma: epidemiology, pathogenesis, and surveillance - implications for sub-Saharan Africa. S Afr Med J. 2018;108(8b):35-40. https://doi.org/10.7196/SAMJ.2018.v1 08i8b.13499.

2. Okeke E, Davwar PM, Roberts L, Sartorius K, Spearman W, Mali A, et al. Epidemiology of liver Cancer in Africa: current and future trends. Semin Liver Dis. 2019;40(2):111-23. https://doi.org/10.1055/s-0039-3399566.

3. Fitzmaurice C, Akinyemiju T, Abera S, Ahmed M, Alam N, Alemayohu MA, et al. The burden of primary liver cancer and underlying etiologies from 1990 to 2015 at the global, regional, and national level results from the global burden of disease study 2015. JAMA Oncol. 2017;3(12):1683-91. https://doi.org/10.1001/JAMAOncol.2017.3055.

4. Sartorius K, Sartorius B, Aldous C, Govender PS, Madiba TE. Global and country underestimation of hepatocellular carcinoma (HCC) in 2012 and its implications. Cancer Epidemiol Elsevier Ltd. 2015;39(3):284-90. https://doi. org/10.1016/j.canep.2015.04.006.

5. Bray F, Ferlay J, Soerjomataram I, Siegel RL, Torre LA, Jamal A. Global cancer statistics 2018: GLOBOCAN estimates of incidence and mortality worldwide for 36 cancers in 185 countries. A Cancer J Clin. 2018;68(6):394-424. https:// doi.org/10.3322/caac.21492.

6. Singal AG, Lampertico $P$, Nahon P. Epidemiology, and surveillance for hepatocellular carcinoma: new trends, journal of hepatology. Eur Assoc Study Liver. 2020;72(2):250-61. https://doi.org/10.1016/j.jhep.2019.08.025.

7. Ferlay J, Shin HR, Bray F, Forman D, Mathers C, Parkin DM. Estimates of worldwide burden of cancer in 2008: GLOBOCAN 2008. Int J Cancer. 2010; 127(12):2893-917. https://doi.org/10.1002/ijc.25516.

8. IARC. Latest global cancer data. IARC Global Cancer Observatory, In: 2018 Sept 12 [. Available from: http://gco.iarc.fr/.

9. Lemoine M, Thursz MR. Battlefield against hepatitis B infection and HCC in Africa. J Hepatol. 2017;66(3):645-54. https://doi.org/10.1016/j.jhep.2016.10. 013.

10. Baecker A, Xing L, Carlo LV, Zuo-Feng Z. Worldwide incidence of hepatocellular carcinoma cases attributable to major risk factors. Eur J Cancer Prev. 2018;27(3):205-12. https://doi.org/10.1097/cej.000000000000042 8.

11. Institute for Health Metrics and Evaluation (IHME). Global Burden of Disease Study 2017. IHME. 2018; 5-23. Available at: http://www.healthdata.org/sites/ default/files/files/policy. [Accessed 5 June 2019].

12. Lin L, Yan L, Liu Y, Qu C, Ni J, Li H. The Burden and Trends of Primary Liver Cancer Caused by Specific Etiologies from 1990 to 2017 at the Global, Regional, National, Age, and Sex Level Results from the Global Burden of Disease Study 2017. Liver Cancer. 2020;9(5):563-82. https://doi.org/10.1159/ 000508568.

13. El-Serag HB. Epidemiology of viral hepatitis and hepatocellular carcinoma'. Gastroenterology. 2012;142(6):1264-73. https://doi.org/10.1053/j.gastro.2 011.12.061.

14. Ndom P. Cancer prevention in Africa: liver cancer. E Cancer Med Sci. 2019; 13(2019):1-8. https://doi.org/10.3332/ecancer.2019.950.

15. Kew MC. Epidemiology of hepatocellular carcinoma in sub-Saharan Africa. Ann Hepatol. 2013;12(2):173-82. https://doi.org/10.1016/S1665-2681(19)313 54-7.
16. Schweitzer A, Horn J, Mikolajczyk RT, Krause G, Ott JJ. Estimations of worldwide prevalence of chronic hepatitis B virus infection: a systematic review of data published between 1965 and 2013. Lancet. 2015;386(10003): 1546-55. https://doi.org/10.1016/S0140-6736(15)61412-X.

17. WHO: Global hepatitis report, In: 2017. Available at https://apps.who.int/iris/ handle/10665/255016 [.

18. Jefferies M, Rauff B, Rashid H, Lam T, Rafiq S. Update on the global epidemiology of viral hepatitis and preventive strategies. World J Clin Cases. 2018;6(13):589-99. https://doi.org/10.12998/wjcc.v6.i13.589.

19. Bigna JJ, Kenne AM, Hamroun A, Ndangang MS, Foka AJ, Tounoung DN, et al. Gender development and hepatitis B and C infections among pregnant women in Africa: a systematic review and meta-analysis. Infect Dis Poverty. 2019;8(1):2-12. https://doi.org/10.1186/s40249-019-0526-8.

20. Nordien R, Sonderup MW, Spearman CW. A decade of hepatitis $C$ at the University of Cape Town/Groote Schuur hospital liver clinic, South Africa, in the pre-direct-acting antivirals era. S Afr Med J. 2020;110(2):106-11. https:// doi.org/10.7196/samj.2020.V110i2.14208.

21. Andernach IE, Leiss LV, Tarnagda ZS, Tahita MC, Otegbayo JA, Forbi JC, et al. Characterization of hepatitis delta virus in sub-Saharan Africa. J Clin Microbiol. 2014;52(5):1629-36. https://doi.org/10.1128/JCM.02297-13.

22. Makhlouf NA, Morsy KH, Mahmoud AA. Hepatitis D virus infection among hepatitis B virus surface antigen-positive individuals in upper Egypt: prevalence and clinical features. Journal of Infection, and Public Health. 2019;12(3):350-6. https://doi.org/10.1016/j.jiph.2018.12.001.

23. Stockdale AJ, Chaponda M, Beloukas A, Philipps RO, Mathew PC, Papadimitropoulos A, et al. Prevalence of hepatitis D virus infection in subSaharan Africa: a systematic review and meta-analysis. Lancet Glob Health. 2017;5(10):e992-e1003. https://doi.org/10.1016/S2214-109X(17)30298-X.

24. Amougou MA, Dominique NN, Moundipa PF, Pineal P, Njouom R. A prominent role of hepatitis $D$ virus in liver cancers documented in Central Africa. BMC Infect Dis. 2016;16(1):2-8. https://doi.org/10.1186/s12879-016-1 992-2.

25. Daw MA, Daw AM, Sifennasr NE, Draha AM, Daw AM, Daw AM, et al. The Epidemiology of Hepatitis D Virus in North Africa: A Systematic Review and Meta-Analysis. Sci World J. 2018;2018:2-11. https://doi.org/10.1155/2018/ 9312650.

26. Beasley RP, Hwang LY, Lin CC, Chien CS. Hepatocellular carcinoma and hepatitis B virus. A prospective study of 22707 men in Taiwan. Lancet. 1981;2(8256):1129-33. https://doi.org/10.1016/s0140-6736(81)90585-7.

27. Zhu RX, Seto W, Lai C, Yuen M. Epidemiology of hepatocellular carcinoma in the Asia-Pacific region. Gut Liver. 2016;10(3):332-9. https://doi.org/10. 5009/gnl15257.

28. Ott JJ, Stevens GA, Groeger J, Wiersma ST. Global epidemiology of hepatitis $B$ virus infection: new estimates of age-specific HBsAg seroprevalence and endemicity. Vaccine. 2012;30(12):2212-9. https://doi.org/10.1016/j.vaccine.2 011.12.116.

29. Breakwell L, Tevi-Benissan C, Childs L, Mihigo R, Tohme R. The status of hepatitis B control in the African region. Pan Afr Med J, 2017;27(Supp 3):17. Doi: 10.11604/pamj.supp.2017.27.3.11981.

30. Ott JJ, Horn J, Kraus G, Mikolajczyk RF. Time trends of chronic HBV infection over prior decades - a global analysis. J Hepatol. 2017;66(1):48-54. https:// doi.org/10.1016/j.jhep.2016.08.013.

31. Tamandjou CR, Maponga TG, Chotun N, Preiser W, Anderson MI. Is hepatitis B birth dose vaccine needed in Africa? Pan Afr Med J. 2017; 27(Supp 3):18. DOI: 10.11604/pamj.supp.2017.27.3.11546.

32. Chang M-H, You S-L, Chen C-J, Liu C-J, Lai M-W, Wu T-C, et al. Long-term effects of hepatitis B immunization of infants in preventing liver Cancer. Gastroenterology. 2016;151(3):472-80. https://doi.org/10.1053/j.gastro.2016.05.048.

33. Cooke GS, Andrieux-Meyer I, Applegate TL, Atun R, Burry JR, Cheinquer $H$, et al. Accelerating the elimination of viral hepatitis : a Lancet Gastroenterology \& Hepatology Commission. Lancet Gastroenterol Hepatol. 2019;4:135-84. https://doi.org/10.1016/S2468-1253(18)30270-X.

34. Adoba P, Boadu SK, Agbodzakey H, Somuah D, Ephraim RKD, Odame EA. High prevalence of hepatitis $B$ and poor knowledge on hepatitis $B$ and $C$ viral infections among barbers: a cross-sectional study of the Obuasi municipality, Ghana. BMC Public Health. 2015;15(1):1-7. https://doi.org/10.11 86/s12889-015-2389-7.

35. Sultan NY, Yacoobmayet A, Alaqeel SA, Al-Omar HA. Assessing the level of knowledge and available sources of information about hepatitis $C$ infection among HCV-infected Egyptians. BMC Public Health. 2018;18(1):1-8. https:// doi.org/10.1186/s12889-018-5672-6. 
36. Luma HN, Eloumou SAFB, Noah DN, Eyenga BA, Nko'Ayissi G, Taku TS, et al. Hepatitis C continuum of Care in a Treatment Center in sub-Saharan Africa, journal of clinical and experimental hepatology. Elsevier BV. 2018;8(4):33541. https://doi.org/10.1016/j.jceh.2018.01.001.

37. WHO: Hepatitis D, In: 2019. Available from: https://www.who.int/newsroom/fact-sheets/detail/hepatitis-d [.

38. Lemoine M, Eholié S, Lacombe K. Reducing the neglected burden of viral hepatitis in Africa: strategies for a global approach, journal of hepatology. Eur Assoc Study Liver. 2015;62(2):469-76. https://doi.org/10.1016/j.jhep.2 014.10.008.

39. Bahri O, Ezzikouri S, Alaya-Bouafif NB, Iguer F, El Feydi AE, Mestiri H, et al. First multicenter study for risk factors for hepatocellular carcinoma development in North Africa. World J Hepatol. 2011;3(1):24-30. https://doi. org/10.4254/wjh.v3.11.24.

40. Kirk GD, Lesi OA, Mandy M, Akano AO, Sam O, Goedert JJ, et al. The Gambia liver Cancer study: infection with hepatitis B and $C$ and the risk of hepatocellular carcinoma in West Africa. Hepatology. 2004;39(1):211-9. https://doi.org/10.1002/hep.20027.

41. Maponga TG, Richard HG, Hannali V, Barbara R, Burmeister S, Vernon M, et al. Hepatitis B virus-associated hepatocellular carcinoma in South Africa in the era of HIV. BMC Gastroenterol. 2020;20(1):1-9. https://doi.org/10.1186/ s12876-020-01372-2

\section{Publisher's Note}

Springer Nature remains neutral with regard to jurisdictional claims in published maps and institutional affiliations.

Ready to submit your research? Choose BMC and benefit from:

- fast, convenient online submission

- thorough peer review by experienced researchers in your field

- rapid publication on acceptance

- support for research data, including large and complex data types

- gold Open Access which fosters wider collaboration and increased citations

- maximum visibility for your research: over $100 \mathrm{M}$ website views per year

At BMC, research is always in progress.

Learn more biomedcentral.com/submissions 